\title{
Germination of seed from five broadleaf weeds after burial for up to 28 years in two soils
}

\author{
T.K. James, A. Rahman and P. Trivedi \\ Ruakura Research Centre, Private Bag 3123, Hamilton 3240, New Zealand \\ Correspondingauthor: trevor.james@agresearch.co.nz
}

\begin{abstract}
Some herbaceous broadleaf weed species are major weeds of pastures and are difficult to manage with ongoing re-infestation from the persistent soil weed seedbank. In this study, seeds from five weed species were collected in 2009 from two sites where they had been buried at three depths since 1981. The species were Scotch thistle (Cirsium vulgare), Californian thistle (Cirsium arvense), nodding thistle (Carduus nutans), ragwort (Jacobaea vulgaris) and giant buttercup (Ranunculus acris). Very few of the seeds were viable after being buried for 28 years in a clay soil, while in a sandy soil seeds of the three thistle species remained viable when buried at $200 \mathrm{~mm}$ depth. It is estimated that these seeds may remain viable for up to 66 years.
\end{abstract}

Keywords buried seed, seed longevity, weed seed, burial depth, soil seedbank, Californian thistle, nodding thistle, Scotch thistle, ragwort, giant buttercup.

\section{INTRODUCTION}

The adage 'one year's seeding makes seven year's weeding', which refers to the persistence of viable seed in the soil, has been shown to be true for many weedy species, particularly when they are buried below their normal emergence zone (Benech-Arnold et al. 2000; Benvenuti et al. 2001). In fact, evidence shows that the seed of some weed species persists for more than seven times that 7 years (Telewski \& Zeevaart 2002). Seed dormancy is a survival mechanism utilised by many weeds, especially broadleaf species (Burnside et al. 1996), and many farmers have reported weeds, such as ragwort (Jacobaea vulgaris) and nodding thistle (Carduus nutans), emerging in large numbers after ploughing when no plants have been present for several years.
The traditional method for studying the longevity and persistence of weed seeds in the soil seedbank is to bury fresh seed in known locations and then dig them up some years later and determine their ability to germinate (e.g. Dawson \& Bruns 1975). This was also the method chosen here to study the longevity of seeds of five serious pasture weeds in 1981. Ragwort, nodding thistle, Scotch thistle (Cirsium vulgare), Californian thistle (C. arvense) and giant buttercup (Ranunculus acris) have all been present in New Zealand for more than one hundred years and were most likely introduced in contaminated grass seed brought into the country by early settlers. These five weeds have a reputation for being difficult to manage as well as inducing significant loss of production 
in pastures (e.g. Harvey \& Bourdôt; Bourdôt \& Saville 2002; Moore et al. 1989).

Results from the first 16 years after the 1981 seed burial experiment have been reported for individual species (James et al. 1998; James \& Rahman 1999, 2000, 2001, 2003). Originally, seed was buried in four different soils in the vicinity of Hamilton. In 2009 all the sites were revisited to remove more seed for evaluation. Unfortunately two of the sites had been destroyed in the interim. This paper summarises the data on the seed viability of these five weed species after 28 years burial at the two remaining sites.

\section{MATERIALS AND METHODS}

The two seed burial sites were located on the Horotiu sandy loam and Hamilton clay loam soils in permanent pasture that was regularly grazed or mown (Table 1). Both soils are of volcanic origin; the Horotiu soil is derived from water-deposited material resulting in a free draining coarse textured soil, while the Hamilton soil has a finer texture and is less free draining, being derived from airdeposited material. During autumn 1981 fresh seed of the five test species was collected, cleaned and tested for germination. Approximately 250 seeds of ragwort $(0.06 \mathrm{~g})$, giant buttercup $(0.31 \mathrm{~g})$ and Californian thistle $(0.26 \mathrm{~g})$ and 200 seeds of Scotch thistle $(0.49 \mathrm{~g})$ and nodding thistle $(0.44 \mathrm{~g})$ were weighed out in preparation for burial.

In June 1981, 90 batches of weighed seed of each of the five species were individually buried at each of the two sites. Each batch was mixed with heat-sterilised soil (60 g) collected from the site and 60 batches were placed in fine nylon mesh bags $(0.25 \mathrm{~mm}$ mesh). Thirty tubes for each site $(250 \mathrm{~mm}$ length of perforated, $60 \mathrm{~mm}$ diameter plastic drainpipe) were filled with nonsterilised soil from the site. During this process, two seed/soil bags were placed in each tube at $50 \mathrm{~mm}$ and $200 \mathrm{~mm}$ from the top end of the pipe. The top $20 \mathrm{~mm}$ of the pipe was left free of soil and an unbagged seed/soil mixture was placed there, separated from the soil below by a layer of fine nylon mesh but uncovered at the top. The pipe sections were then buried vertically in the appropriate soil type with their tops flush with the soil surface. The tubes were arranged in a regular $10 \times 3$ matrix at $200 \mathrm{~mm}$ centres.

At 2-4 month intervals for the first 3 years after burial, emerged seedlings were counted and removed from the tops of the pipe sections. After $1,2,3,5,11,16$ and 28 years, three randomly selected pipes were retrieved from each site in June or July and the viable seed from each depth counted. Seed viability was determined by germination in an unheated glasshouse. The contents of each nylon bag and the $0-20 \mathrm{~mm}$ layer were spread thinly $(2-4 \mathrm{~mm})$ on paper towels laid over damp vermiculite in a tray. At approximately monthly intervals, emerged seedlings were counted and removed. The soil was then thoroughly mixed and the procedure repeated until no further seedlings emerged (4-6 months). On completion of the final incubation the seed/soil mixtures were washed to remove fine particles and then dry sieved to remove large particles. The remaining soil was searched for ungerminated seeds.

Exponential (decay) curves were fitted to all data using the regression command in Minitab and the time taken for the viable seed to fall to $1 \%$ of the original amount calculated from the equation for this line. Coefficients of determination $\left(\mathrm{R}^{2}\right)$ are presented as an indication of the amount of variation accounted for by both variables.

\section{RESULTS AND DISCUSSION}

The viability of the original seed, as determined by the Official Seed Testing Station, Palmerston North, was $80 \%$ for Scotch thistle, $81.5 \%$ for nodding thistle, 70\% for Californian thistle, $43 \%$ for giant buttercup and $69 \%$ for ragwort. This value was used to determine the theoretical initial number of viable seeds (Time 0 , Table 2) buried at each depth. This number was higher than subsequent germination after 1 year for all species except giant buttercup where the low initial germination of just $43 \%$ appears to be incorrect as germination in year 1 was as high as $75 \%$.

Results for all the five species show that seed viability was affected most by the burial depth, with a rapid decline in emergence of seed in the 1-20 mm burial zone compared with a much 
Table 1 Some characteristics of the two soils in which seeds were buried.

\begin{tabular}{lcccccc}
\hline Soil & \% sand & \% clay & \% OC & pH & $\begin{array}{c}\text { CEC }^{1} \\
\text { meq/100g }\end{array}$ & $\begin{array}{c}\text { Field capacity } \\
\text { (\% v/v) }\end{array}$ \\
\hline Horotiu sandy loam & 61 & 15 & 8.7 & 5.4 & 37.4 & 44.8 \\
Hamilton clay loam & 29 & 31 & 4.6 & 5.6 & 28.2 & 36.8 \\
\hline
\end{tabular}

${ }^{1} \mathrm{OC}=$ Organic carbon; $\mathrm{CEC}=$ Cation exchange capacity.

extended seed viability at a depth of $200 \mathrm{~mm}$. Seeds of Scotch thistle and giant buttercup buried in the top $20 \mathrm{~mm}$ of the soil mostly disappeared within the first year, with seeds germinating only occasionally in the next few years (Table 2). Nodding thistle seed in the surface layer suffered a fate similar to the above two species, although a very small number was found viable until year 11 (Table 2). In contrast, Californian thistle and ragwort were found to have significant numbers of viable seed in the top $20 \mathrm{~mm}$ for up to 5 years; even after 11 years there were a few viable seeds remaining (Table 2). For all the species, however, the seeds placed in the surface layer lost their viability at a faster rate than at the 50 and $200 \mathrm{~mm}$ depths. No seeds were found in the soil after the germination incubation period showing that all viable seeds had germinated and the remaining seeds had disappeared, probably through decay.

Some of the Scotch thistle, nodding thistle

Table 2 Number of seeds germinating over time after burial at different depths in two soils, the coefficient of determination $\left(\mathrm{R}^{2}\right)$ of the calculated exponential decay curve and the predicted time (years) for seed viability to decline to $1 \%$.

\begin{tabular}{|c|c|c|c|c|c|c|}
\hline \multirow{3}{*}{$\begin{array}{l}\text { Burial } \\
\text { time (years) }\end{array}$} & \multirow{2}{*}{\multicolumn{3}{|c|}{$\begin{array}{l}\text { Horotiu sandy loam } \\
\text { Burial depth (mm) }\end{array}$}} & \multirow{2}{*}{\multicolumn{3}{|c|}{$\begin{array}{l}\text { Hamilton clay loam } \\
\text { Burial depth (mm) }\end{array}$}} \\
\hline & & & & & & \\
\hline & $1-20$ & 50 & 200 & $1-20$ & 50 & 200 \\
\hline \multicolumn{7}{|l|}{ Scotch thistle } \\
\hline 0 & 159 & 159 & 159 & 159 & 159 & 159 \\
\hline 1 & 3 & 76 & 120 & 0 & 69 & 134 \\
\hline 2 & 3 & 79 & 125 & 1 & 57 & 104 \\
\hline 3 & 2 & 49 & 120 & 0 & 51 & 106 \\
\hline 5 & 0 & 56 & 85 & 0 & 25 & 100 \\
\hline 11 & 1 & 57 & 71 & 0 & 17 & 29 \\
\hline 16 & 0 & 18 & 74 & 0 & 5 & 5 \\
\hline 28 & 0 & 0 & 15 & 0 & 0 & 0 \\
\hline Time to $1 \%$ & 3.6 & 16.9 & 62.2 & 1.2 & 15.1 & 16.1 \\
\hline $\mathrm{R}^{2}(\%)$ & 49.8 & 81.3 & 90.9 & 83.6 & 91.8 & 92.8 \\
\hline \multicolumn{7}{|c|}{ nodding thistle } \\
\hline 0 & 163 & 163 & 163 & 163 & 163 & 163 \\
\hline 1 & 3 & 87 & 108 & 1 & 115 & 137 \\
\hline 2 & 7 & 100 & 118 & 2 & 86 & 81 \\
\hline 3 & 1 & 63 & 110 & 1 & 48 & 77 \\
\hline 5 & 1 & 63 & 97 & 1 & 28 & 89 \\
\hline 11 & 5 & 69 & 57 & 0 & 24 & 22 \\
\hline 16 & 0 & 46 & 52 & 0 & 0 & 1 \\
\hline 28 & 0 & 1 & 5 & 0 & 0 & 0 \\
\hline Time to $1 \%$ & 6.1 & 30.7 & 41.9 & 3.2 & 10.4 & 14.7 \\
\hline $\mathrm{R}^{2}(\%)$ & 58.3 & 81.6 & 92.1 & 76.4 & 78.2 & 96.3 \\
\hline
\end{tabular}




\begin{tabular}{|c|c|c|c|c|c|c|}
\hline \multirow{2}{*}{$\begin{array}{l}\text { Burial } \\
\text { time (years) }\end{array}$} & \multicolumn{3}{|c|}{$\frac{\text { Horotiu sandy loam }}{\text { Burial depth }(\mathrm{mm})}$} & \multicolumn{3}{|c|}{$\begin{array}{l}\text { Hamilton clay loam } \\
\text { Burial depth }(\mathrm{mm})\end{array}$} \\
\hline & $1-20$ & 50 & 200 & $1-20$ & 50 & 200 \\
\hline \multicolumn{7}{|c|}{ Californian thistle } \\
\hline $\begin{array}{c}0 \\
1 \\
2 \\
3 \\
5 \\
11 \\
16 \\
28\end{array}$ & $\begin{array}{r}175 \\
51 \\
34 \\
31 \\
25 \\
4 \\
1 \\
0\end{array}$ & $\begin{array}{r}175 \\
157 \\
113 \\
112 \\
87 \\
82 \\
37 \\
2\end{array}$ & $\begin{array}{r}175 \\
181 \\
172 \\
139 \\
134 \\
92 \\
101 \\
20\end{array}$ & $\begin{array}{r}175 \\
49 \\
18 \\
16 \\
11 \\
0 \\
0 \\
0\end{array}$ & $\begin{array}{r}175 \\
142 \\
77 \\
66 \\
34 \\
9 \\
2 \\
0\end{array}$ & $\begin{array}{r}175 \\
135 \\
108 \\
124 \\
97 \\
15 \\
14 \\
1\end{array}$ \\
\hline $\begin{array}{l}\text { Time to } 1 \% \\
\mathrm{R}^{2}(\%)\end{array}$ & $\begin{array}{l}12.8 \\
98.3 \\
\end{array}$ & $\begin{array}{l}32.9 \\
91.0 \\
\end{array}$ & $\begin{array}{l}65.9 \\
90.9 \\
\end{array}$ & $\begin{array}{r}5.5 \\
95.3 \\
\end{array}$ & $\begin{array}{l}14.3 \\
97.9 \\
\end{array}$ & $\begin{array}{l}25.4 \\
97.6 \\
\end{array}$ \\
\hline $\begin{array}{c}\text { giant butterc } \\
0 \\
1 \\
2 \\
3 \\
5 \\
11 \\
16 \\
28\end{array}$ & $\begin{array}{r}108 \\
0 \\
1 \\
0 \\
0 \\
0 \\
0 \\
0\end{array}$ & $\begin{array}{r}108 \\
64 \\
6 \\
5 \\
6 \\
4 \\
1 \\
0\end{array}$ & $\begin{array}{r}108 \\
118 \\
107 \\
96 \\
47 \\
41 \\
19 \\
0\end{array}$ & $\begin{array}{r}108 \\
1 \\
1 \\
1 \\
0 \\
1 \\
0 \\
0\end{array}$ & $\begin{array}{r}108 \\
66 \\
6 \\
13 \\
4 \\
1 \\
0 \\
0\end{array}$ & $\begin{array}{r}108 \\
172 \\
115 \\
123 \\
52 \\
18 \\
1 \\
0\end{array}$ \\
\hline $\begin{array}{l}\text { Time to } 1 \% \\
\mathrm{R}^{2}(\%)\end{array}$ & $\begin{array}{r}1.0 \\
45.7 \\
\end{array}$ & $\begin{array}{l}12.9 \\
88.5 \\
\end{array}$ & $\begin{array}{l}18.2 \\
84.1 \\
\end{array}$ & $\begin{array}{r}3.3 \\
40.4 \\
\end{array}$ & $\begin{array}{r}8.1 \\
91.6 \\
\end{array}$ & $\begin{array}{l}15.8 \\
97.0 \\
\end{array}$ \\
\hline $\begin{array}{r}\text { ragwort } \\
0 \\
1 \\
2 \\
3 \\
5 \\
11 \\
16 \\
28\end{array}$ & $\begin{array}{r}172 \\
98 \\
74 \\
55 \\
43 \\
13 \\
0 \\
0\end{array}$ & $\begin{array}{r}172 \\
159 \\
138 \\
133 \\
116 \\
53 \\
8 \\
0\end{array}$ & $\begin{array}{r}172 \\
185 \\
138 \\
127 \\
130 \\
81 \\
13 \\
0\end{array}$ & $\begin{array}{r}172 \\
80 \\
69 \\
37 \\
44 \\
3 \\
0 \\
0\end{array}$ & $\begin{array}{r}172 \\
156 \\
149 \\
159 \\
160 \\
4 \\
0 \\
0\end{array}$ & $\begin{array}{r}172 \\
196 \\
148 \\
161 \\
179 \\
6 \\
0 \\
0\end{array}$ \\
\hline $\begin{array}{l}\text { Time to } 1 \% \\
\mathrm{R}^{2}(\%)\end{array}$ & $\begin{array}{r}9.8 \\
82.6 \\
\end{array}$ & $\begin{array}{l}16.6 \\
90.2 \\
\end{array}$ & $\begin{array}{l}17.2 \\
86.6 \\
\end{array}$ & $\begin{array}{r}9.0 \\
91.3 \\
\end{array}$ & $\begin{array}{r}9.9 \\
88.2 \\
\end{array}$ & $\begin{array}{l}10.1 \\
86.5\end{array}$ \\
\hline
\end{tabular}

and giant buttercup seeds placed in the top layer germinated in the field, mostly during the first 2 years but this accounted for less than $20 \%$ of the initial amounts of viable seed (James et al. 1998; James \& Rahman 1999, 2003). Thus nearly $80 \%$ of the viable seed placed in the top $20 \mathrm{~mm}$ remained unaccounted for, which suggests that under normal field conditions much of the seed of these species that falls to the ground is lost within the first year unless it is quickly buried. This rapid disappearance of the seed from the top layer of soil, particularly in the case of giant buttercup, means that long term control of this weed should be readily attainable if seed production is eliminated before the plants are killed. The case was markedly different for Californian thistle and ragwort, however, where significant numbers of seeds continued to germinate, particularly over the first 5 years but also up to 11 years, confirming the longer viability of seed from these two than 
the other three species. This relatively long persistence of viable seed of Californian thistle and ragwort in the surface layer poses serious management problems for these weeds. Even if additions of fresh seed to the soil are eliminated, the remaining viable seed in the seedbank could still produce infestations for more than 10 years.

Seed buried at $200 \mathrm{~mm}$ depth remained viable for a longer period than at the shallower depth of $50 \mathrm{~mm}$. Nodding thistle appeared to be the only species for which after 16 years there was little difference in seed viability due to burial depth. Deep burial has been found by many researchers to induce dormancy rather than suicide germination in most weed species (e.g. Dawson \& Bruns 1975; Benvenuti et al.2001). The ability to retain viability longer at the greater depth of $200 \mathrm{~mm}$ (cf. $50 \mathrm{~mm}$ ) was most obvious in the case of giant buttercup and much less so in the case of ragwort. This further highlights the difficulty in managing a weed like ragwort where seed remains viable longer than many other species on the surface layer as well as when buried in deeper layers of the soil.

Two species, giant buttercup and ragwort, which were found to have small numbers of viable seed after 16 years of burial in the Horotiu soil, did not have any viable seed at any depth in either soil type after 28 years (Table 2). The three thistle species, viz. Scotch, nodding and Californian, which had some viable seed present at 50 and/ or $200 \mathrm{~mm}$ depths after 16 years of burial in both soil types, were found to have some viable seed even after 28 years in the Horotiu soil (Table 2). In contrast, no viable seed were noted for any species in the Hamilton soil, except for a single Californian thistle seed buried at the $200 \mathrm{~mm}$ depth (Table 2). The additional data obtained at 28 years enabled new fitted exponential decay curves to be calculated and compared with those presented in earlier publications for the 16-year data set (James et al. 1998, James \& Rahman 1999, 2000, 2001, 2003). Generally the fitted exponential decay curves over the 28 years were good descriptions of the data, as evident from high $\mathrm{R}^{2}$ values (Table 2 ). However, the fit for ragwort was not as good as for other species because it tended to persist without loss of viability for about 5 years after which the viability declined rapidly. This could be related to the seed size as ragwort has the smallest seed of the species evaluated. From the 28-year data it would appear that the seed viability of these weed species was not as long in most cases as was predicted based on our 16-year results. As the predictions were mostly extrapolations from the 16-year data, it is quite plausible that our estimates of the longevity of seed buried at the 50 and $200 \mathrm{~mm}$ depths were over-estimated. For example, James et al. (1998) estimated the longevity of nodding thistle to be 6 , 79 and 67 years at $0-20,50$ and $200 \mathrm{~mm}$ depths respectively in the Horotiu soil. Based on the data presented here, these estimates have been revised to 6,31 and 42 years respectively due to a greater decline in seed viability between 16 and 28 years than originally predicted from the 16-year data.

Seeds of all three thistle species retained greater viability in the Horotiu sandy loam soil compared to the Hamilton clay loam soil. The Hamilton soil has a heavier texture, lower water holding capacity (Table 1) and is more prone to drying. All these characteristics are likely to be associated with the more rapid depletion of the weed seedbank as they aid scarification of the seed coat allowing imbibition to commence and the seed then either germinates or decays. In the absence of scarification processes, several species were shown to retain $90 \%$ viability after 110 years when stored at ambient temperature in sealed containers (Steiner \& Ruckenbauer 1995).

Although the results of seed viability after 28 years burial presented here show shorter longevity of buried seed, it is probably of little comfort to farmers as 1 years seeding could still result in the need for 10 to 66 years weeding, depending on the weed species and soil type.

\section{REFERENCES}

Benech-Arnold RL, Sanchez RA, Forcella F, Kruk BC, Ghersa MM 2000. Environmental control of dormancy in weed seedbanks in soil. Field Crops Research 67: 105-122.

Benvenuti S, MacChia M, Miele S 2001. Quantitative analysis of emergence of seedlings from buried weed seeds with increasing soil depth. Weed Science 49: 528-535. 
Bourdôt GW, Saville DJ 2002. Estimating economic losses due to pasture weeds. New Zealand Plant Protection 55:106-110.

Burnside OC, Wilson RG, Weisberg S, Hubbard KG 1996. Weed longevity of 41 weed species buried 17 years in eastern and western Nebraska. Weed Science 44: 74-86.

Dawson JH, Bruns VF 1975. Longevity of barnyard grass, green foxtail, and yellow foxtail seeds in soil. Weed Science 23: 437-440.

Harvey IC, Bourdôt 2001. Giant buttercup (Ranunculus acris 1.) control in dairy pasture using a mycoherbicide based on Sclerotinia sclerotiorum. New Zealand Plant Protection 54: 120-124.

James TK, Rahman A, Wardle DA, Bonner KI 1998. Survival of nodding thistle (Carduus nutans) seed buried at different depths in four soils. Proceedings of the 51st New Zealand Plant Protection Conference: 33-37.

James TK, Rahman A 1999. Survival of giant buttercup seed buried at different soil depths in four soils. Proceedings of the 52nd New Zealand Plant Protection Conference: 234-239.
James TK, Rahman A 2000. Longevity of buried ragwort seed in four soils. New Zealand Plant Protection 53: 253-257.

James TK, Rahman A 2001. Longevity of buried Cirsium arvense seed in four New Zealand soils. Proceedings of the $18^{\text {th }}$ Asian-Pacific Weed Science Society Conference:. 33-38.

James TK, Rahman A 2003. Survival of Scotch thistle seed buried at three depths in four New Zealand soils. New Zealand Plant Protection 56: 113-117.

Moore WB, Doyle CJ, Rahman A 1989. Economics of controlling Carduus nutans on grazed pasture in New Zealand. Crop Protection 8: 16-24.

Steiner AM, Ruckenbauer P 1995. Germination of 110-year-old cereal and weed seeds, the Vienna Sample of 1877 . Verification of effective ultra-dry storage at ambient temperature. Seed Science Research 5: 195-199.

Telewski FW, Zeevaart JAD 2002. The 120-yr period for Dr. Beal's seed viability experiment. American Journal of Botany 89: 1285-1288. 